\title{
Nutrient deprivation in neuroblastoma cells alters 4-hydroxynonenal-induced stress response
}

\author{
Lars Zimmermann ${ }^{1}$, Rudolf Moldzio², Katarina Vazdar ${ }^{3}$, Christopher Krewenka ${ }^{2}$, \\ Elena E. Pohl ${ }^{1}$ \\ ${ }^{1}$ Institute of Physiology, Pathophysiology and Biophysics, Department of Biomedical Sciences, University of Veterinary \\ Medicine, Vienna, Austria \\ ${ }^{2}$ Institute of Medical Biochemistry, Department of Biomedical Sciences, University of Veterinary Medicine, Vienna, Austria \\ ${ }^{3}$ Division of Organic Chemistry and Biochemistry, Rudjer Boskovic Institute, Zagreb, Croatia \\ Correspondence to: Elena E. Pohl, email: elena.poh/@vetmeduni.ac.at \\ Lars Zimmermann, email: lars.zimmermann@vetmeduni.ac.at \\ Keywords: cancer cell metabolism, mitochondrial membrane potential, starvation, oxononenal, B-oxidation \\ Received: July 11,2016 Accepted: November 21, $2016 \quad$ Published: December 24, 2016
}

\section{ABSTRACT}

4-hydroxy-2-nonenal (HNE), a toxic lipid peroxidation product, is associated with oxidative damage in cells and involved in various diseases including the initiation and progression of cancer. Cancer cells have a high, adaptable metabolism with a shift from oxidative phosphorylation to glycolysis and rely on high levels of glucose and glutamine as essential nutrients for cell growth. Here we investigated whether the toxic effects of HNE on the mitochondrial membrane potential (MMP) of cancer cells depends on their metabolic state by deprivation of glucose and/or glutamine. The addition of $16 \mu \mathrm{M}$ HNE to N18TG2 neuroblastoma cells incubated in glucose medium led to a severe reduction of MMP, which was similar to the MMP of cells fed with both glucose and glutamine. In contrast, HNE addition to cells starved in glutamine medium increased their MMP slightly for a prolonged time period and this was accompanied by increased cellular survival. We found that B-oxidation of HNE did not cause the increased MMP, since the aldehyde dehydrogenase was distinctly more active in cells with glucose medium. However, after blocking fatty acid B-oxidation in cells starved in glutamine medium with etomoxir, which inhibits carnitine palmitoyltransferase 1, HNE addition induced a strong reduction of MMP similar to cells in glucose medium. Surprisingly, the effect of more toxic 4-oxo-2-nonenal was less pronounced. Our results suggest that in contrast to cells fed with glucose, glutamine-fed cancer cells are capable of B-oxidizing fatty acids to maintain their MMP to combat the toxic effects of HNE.

\section{INTRODUCTION}

Mitochondria are the major source for the generation of ROS such as superoxide, hydrogen peroxide and lipid hydroperoxide products [1-3]. Reactive aldehydes such as HNE, oxononenal (ONE) and others are generally formed by oxidation of $\omega-6$ polyunsaturated fatty acids (PUFAs) such as arachidonic acid or linoleic acid by proton abstracting agents (e.g. hydroxyl radicals) $[4,5]$. HNE may also be generated by oxidation of cardiolipin [6], which is a component of the inner mitochondrial membrane. HNE interacts with DNA, proteins containing the amino acids cysteine, lysine or histidine, and lipids containing amino groups (e.g. phosphatidylethanolamine) [7-10]. With proteins and lipids HNE forms Michael and Schiff base adducts $[11,12]$.

The physiological level of HNE in plasma is in the range of $0.07-0.7 \mu \mathrm{M}[13,14]$. At these concentrations HNE was reported to be involved in cellular signalling pathways to regulate proliferation, differentiation and apoptosis [14-16] and to control the cellular antioxidant defence system [17-19]. Under toxic conditions the local concentrations can be quite high and reach $100 \mu \mathrm{M}$ at the plasma membrane [20] leading to oxidative damage, loss of mitochondrial membrane potential (MMP) and cell death. 
HNE is degraded rapidly within cells, in hepatocytes the half-life of $100 \mu \mathrm{M}$ HNE is $\sim 5 \mathrm{~min}$ [21], in human endothelial cells $95 \%$ of $5 \mu \mathrm{M}$ HNE is removed within 30 minutes [22]. There are three major pathways for HNE detoxification. (i) The majority of HNE is removed by reacting with abundant antioxidant glutathione directly or via glutathione-S-transferases, (ii) alcohol dehydrogenases or aldo-keto reductases convert HNE to 1,4-dihydroxy2-nonene (DHN); and iii) aldehyde dehydrogenases (ALDHs) oxidize HNE to 4-hydroxy-2-nonenoic acid (HNA) [23]. HNE adducts can be removed from the cell by excretion or by autophagic and proteosomal degradation [24, 25].

HNE affects various cellular pathways, which change cell proliferation and survival, mitochondrial function and cellular metabolism [26] and has thus been associated with the initiation and progression of cancer $[27,28]$. Cancer cells in general have a high cellular metabolism with a higher glucose uptake and a shift from oxidative phosphorylation to aerobic glycolysis, the so-called Warburg effect [29]. This higher metabolism typically leads to higher production of HNE, which is counteracted by an increased antioxidant system in cancer cells with elevated levels of ALDHs, superoxide dismutases, thioredoxins, glutaredoxins and peroxiredoxins [30-33]. Additionally, the enhanced glucose metabolism stimulates the production of pyruvate and NADPH, that helps to detoxify HNE by increasing levels of the reduced form of glutathione [34]. Furthermore, cancer cells increase the conversion of glutamine, which is essential for cancer growth, into glutathione to reduce HNE levels [35].

Since cancer cell growth and survival strongly depend on high levels of glucose and glutamine as nutrients, deprivation of these nutrients has been utilized as anti-cancer treatment, although this application has been hampered, since cancer cells have the ability to adapt their metabolism [35, 36]. Glucose deprivation in cancer cells is associated with inhibition of HNE detoxification due to reduced levels of NADPH and pyruvate leading to increased oxidative stress and potentially cell death $[37,38]$. Inhibition of cancer cell growth has also been shown by deprivation of glutamine [39]. Both glucose and glutamine deprivation increase autophagy [40-42], which in succession promotes cellular survival by recycling cellular compartments and by protecting against oxidative damage. However, it is still not understood how HNE, generated by oxidative damage, acts on the mitochondrial metabolism under such deprivation conditions, and whether there is a difference between glucose and glutamine deprivation. In differentiated SH-SY5Y neuroblastoma cells, deprivation of glucose increased HNE-induced toxicity [38]. However, cells were deprived of glucose by inhibition of glycolysis with either 2-deoxyglucose or koningic acid, which both also inhibited the autophagic flux. The latter could be an explanation for higher HNE toxicity.
In this work, we aimed to investigate whether the toxic effect of HNE on the MMP of cancer cells depends on metabolic conditions. For this, murine N18TG2 neuroblastoma cells were incubated in medium containing either glucose or glutamine as a nutrient or both glucose and glutamine before HNE was added and then changes of the MMP and cell viability were measured. To gain mechanistic insight, we used inhibitors against involved metabolic pathways. Additionally, we analysed whether our observed effects are specific for HNE by measuring the more reactive aldehyde ONE.

\section{RESULTS AND DISCUSSION}

\section{Addition of 4-hydroxy-2-nonenal (HNE) to N18TG2 neuroblastoma cells decreases mitochondrial membrane potential (MMP) and changes cellular morphology}

As a cancer cell model, we used murine N18TG2 neuroblastoma cells, which have high levels of acetylcholinesterase and are unable to establish synaptic contacts, because the choline acetyltransferase is hardly expressed. First, we tested the effect of HNE on MMP under normal nutrient conditions (DMEM medium with $21.6 \mathrm{mM}$ glucose, $3.85 \mathrm{mM}$ glutamine, $9.6 \%$ fetal bovine serum and 1.92 sodium pyruvate) at $37^{\circ} \mathrm{C}$ and $5 \% \mathrm{CO}_{2}$. To track MMP changes, cells at a cell density of 100 cells/ $\mathrm{mm}^{2}$ were incubated for $20 \mathrm{~min}$ with the potential sensitive dye tetramethylrhodamine (TMRE, $12.5 \mathrm{nM}$ ) (Figure 1A). Then HNE was dissolved in ethanol and added to cells at a final concentration of $16 \mu \mathrm{M}$. Fluorescence change was determined every 3 minutes for one hour by recording Z-stacks using a confocal laser scanning microscope (Figure 1B-1D). Since $16 \mu \mathrm{M}$ HNE is already rather toxic for cells [43], its addition led to a strong reduction of MMP by about $45 \%$ within one hour of incubation (Figure 1C). Control measurements with ethanol had no effect on the MMP (Figure 1D). Alongside with the effects on the MMP, HNE also induced changes in cells morphology even after 5-10 minutes after its addition (Figure 1B).

Data for several cancer cell lines has shown that mitochondria are dysfunctional in regard to energy production and the MMP is hyperpolarized [44-46], but other cancer cell lines exhibit active oxidative phosphorylation [47, 48]. We found that N18TG2 cells possess functional, energy-producing mitochondria, which can be seen, above all, by the strong increase of MMP after addition of oligomycin (Figure 2A). Next, we investigated whether modification of respiratory chain complexes by HNE causes the observed reduction of MMP. For this, we inhibited each complex for $30 \mathrm{~min}$ with an appropriate inhibitor (Figure 2A) and subsequently determined whether HNE-induced MMP reduction was affected. In the presence of complex III inhibitor antimycin or complex 

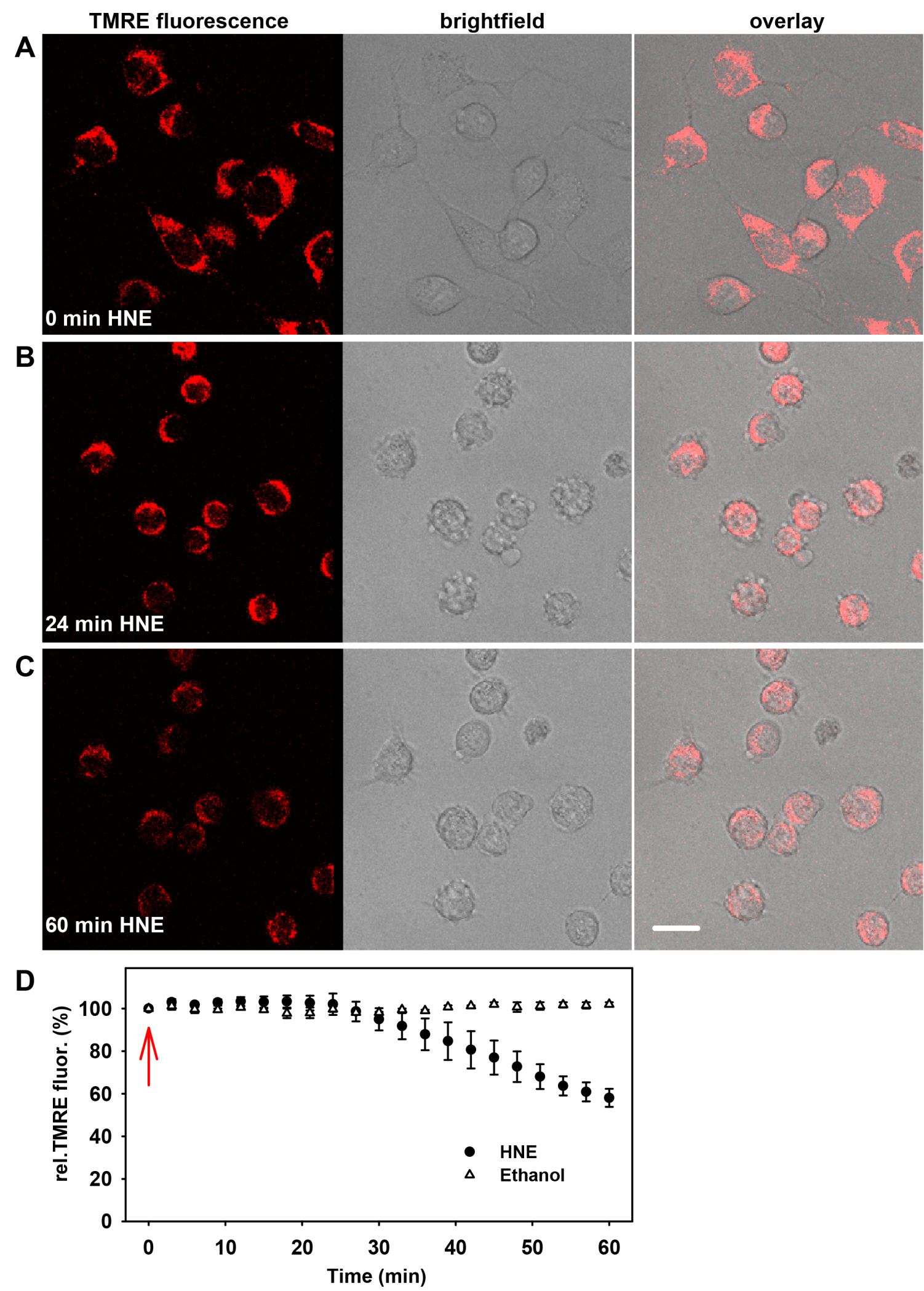

Figure 1: Alteration of the mitochondrial membrane potential and cellular morphology after addition of 4-hydroxy2-nonenal (HNE) to N18TG2 neuroblastoma cells in a typical experiment. A-C. Fluorescence (left), brightfield (middle) and merged (right) images of the cells were recorded A. without HNE, B. 24 minutes and C. 60 minutes after addition of $16 \mu \mathrm{M} \mathrm{HNE}$. Cell medium contained $21.6 \mathrm{mM}$ glucose, $3.85 \mathrm{mM}$ glutamine, $9.6 \%$ fetal bovine serum and $1.92 \mathrm{mM}$ sodium pyruvate. Scale bar is $20 \mu \mathrm{m}$. D. Time course of normalized TMRE fluorescence after addition of $16 \mu \mathrm{M} \mathrm{HNE}$ and ethanol as a control (arrow). TMRE fluorescence was normalized to the fluorescence at time point $0 \mathrm{~min}$. Data are presented as mean values \pm SEM from at least 5 independent experiments. 


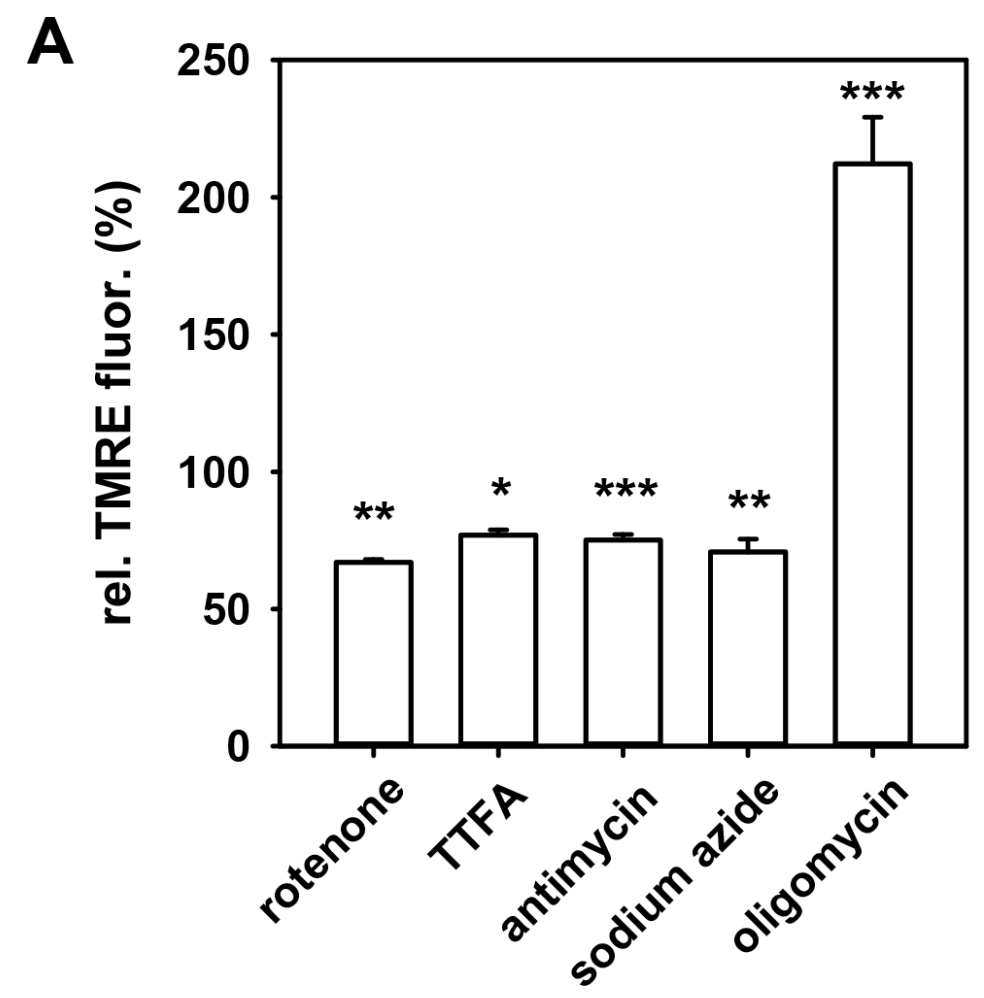

B

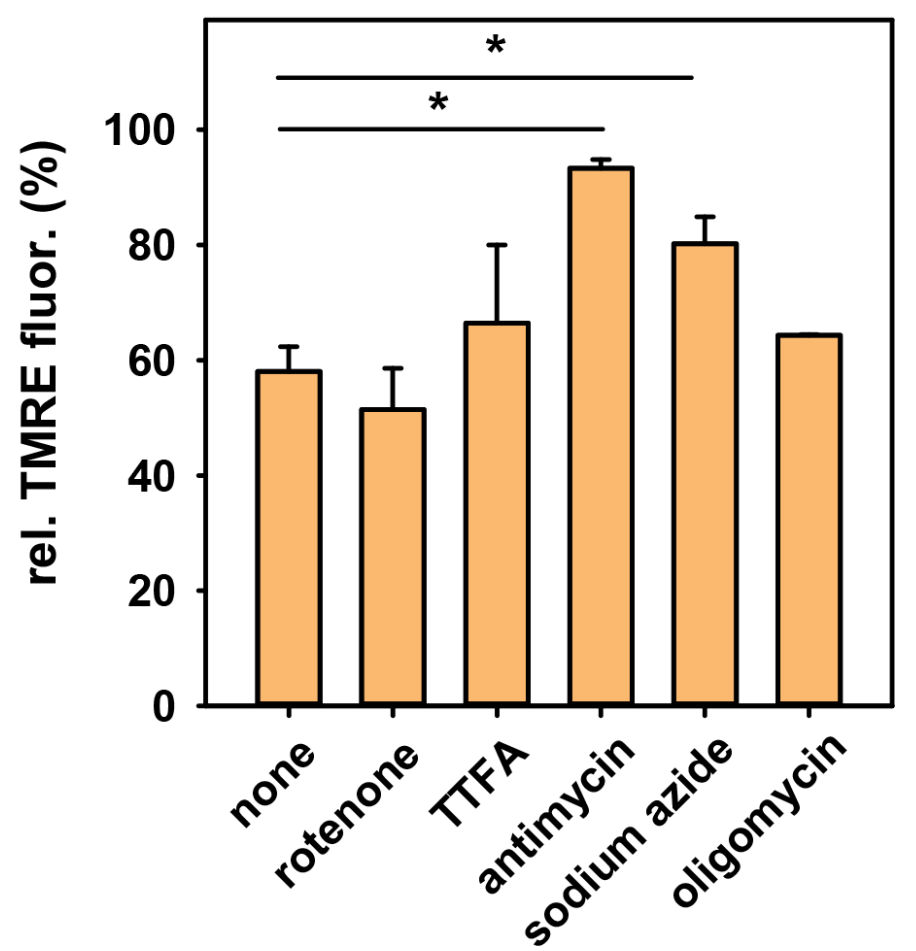

Figure 2: Effect of respiratory chain complexes inhibition on the mitochondrial membrane potential in N18TG2 cells A. in the absence and B. in the presence of HNE. TMRE-stained cells were incubated with inhibitors of complex I (10 nM rotenone), complex II ( $0.5 \mathrm{mM}$ TTFA), complex III (50 $\mu \mathrm{M}$ antimycin A), complex IV (10 $\mu \mathrm{M}$ sodium azide) and complex V ( $2 \mu \mathrm{M}$ oligomycin). TMRE fluorescence measured 30 minutes after addition of inhibitors was normalized to the fluorescence in the absence of the inhibitors (control with ethanol). The final concentration of HNE was $16 \mu \mathrm{M}$. Data are presented as mean values \pm SEM. $* \mathrm{p}<0.05,{ }^{* *} \mathrm{p}<0.01, * * *$ $\mathrm{p}<0.001$. 
IV inhibitor sodium azide, HNE just slightly reduced the MMP (Figure 2B), indicating that the activity of these two complexes are affected the most by HNE modification, which is in line with other studies [49]. In contrast, inhibition of complexes I, II and V (ATP-synthase) with rotenone, thenoyltrifluoroacetone or oligomycin hardly affected the HNE-mediated MMP decrease.

The effect of HNE on the MMP was dependent on the cell concentration. For example, for a sixfold higher cell concentration $\left(600\right.$ cells $\left./ \mathrm{mm}^{2}\right) 64 \mu \mathrm{M}$ HNE was necessary for the same MMP alteration as $16 \mu \mathrm{M}$ at the lower cell density. Therefore, we kept the cell density for each measurement constant at 100 cells $/ \mathrm{mm}^{2}$.

\section{HNE-mediated MMP alteration depends on the type of available nutrient}

Depending on the medium, cancer cells can adapt their metabolism under starvation conditions either in the direction of glycolysis in the presence of only glucose or oxidative phosphorylation, if only glutamine is present [50]. Next, we determined whether the action of HNE on the MMP is affected by the type of nutrient deprivation. As a control, we analysed the effect of HNE on cells incubated in DMEM medium containing both $24.5 \mathrm{mM}$ glucose and $3.85 \mathrm{mM}$ glutamine, but no FCS and pyruvate. Incubation for $2 \mathrm{~h} 30 \mathrm{~min}$ in this medium without HNE reduced the MMP by $\sim 25 \%$ (Figure $3 \mathrm{~A}$; insert). The subsequent addition of HNE led to a strong reduction of the MMP (50\%) similar to that which was observed in the full medium (45\%, Figure 1D). We revealed that the $2 \mathrm{~h} 30 \mathrm{~min}$ starvation in DMEM medium containing $25 \mathrm{mM}$ glucose, but no glutamine (from now on referred as "glucose medium"), had no effect on the MMP (Figure 3A; insert). HNE addition led to an even stronger reduction of the MMP (Figure 3A, downpointing triangles) compared to the experiment with cells incubated with both glucose and glutamine (Figure 3A, circles). Cell starvation in DMEM medium containing $3.85 \mathrm{mM}$ glutamine but no glucose (from now on referred as "glutamine medium") reduced the MMP by $\sim 30 \%$ (Figure 3A; insert). Interestingly, the addition of HNE to these cells did not decrease the MMP within the same incubation time (Figure 3A, up-pointing triangles). It was even slightly increased by $\sim 20 \%$ during the first hour, probably due to higher substrate availability for oxidative phosphorylation.

We also tested whether the strong difference in the HNE-altered MMP between cells kept in glucose and glutamine media is dependent on the glucose concentration, since the normal glucose concentration of the N18TG2 neuroblastoma medium is quite high (>20 mM). However, no difference between $1 \mathrm{mM}, 5 \mathrm{mM}$ and $25 \mathrm{mM}$ glucose in the medium could be observed (Figure 3B). Also, DMEM alone, without any addition of further nutrients showed roughly the same reduction of the MMP after cell treatment with HNE as in the glucose medium (Figure 3B), indicating that both lack of glucose and the presence of glutamine are necessary for the maintenance of MMP.

\section{$\beta$-oxidation of HNE is not the reason for cells fed with glutamine to maintain MMP}

To gain some mechanistic insight we first tested, whether the ATP synthase runs in reverse mode (ATP hydrolysis) under glucose deprivation keeping a high MMP, as described for several cell types under starvation conditions [51, 52]. For this, we added $2 \mu \mathrm{M}$ oligomycin, the inhibitor of the ATP synthase, which was expected to reduce MMP in case the enzyme would work in reverse mode. However, Figure 3C shows that oligomycin addition to cells incubated $2 \mathrm{~h} 30 \mathrm{~min}$ in glutamine medium increased the MMP by $\sim 80 \%$, which indicates that the ATP synthase functioned in normal mode.

To test whether HNE is converted to 4-hydroxynonanoic acid (HNA) by the aldehyde dehydrogenase (ALDH), followed by its $\beta$-oxidation and subsequent increase of substrates for oxidative respiration, we blocked the ALDH by the competitive inhibitor diethylaminobenzaldehyde (DEAB, $50 \mu \mathrm{M})$ in cells kept in glutamine medium. Figure $4 \mathrm{~A}$ shows that after preincubation with DEAB and after addition of HNE, cells could no longer maintain their MMP and its decrease was comparable to that observed in cells kept in glucose medium. Thus, we first hypothesized that $\beta$-oxidation of HNE is a likely cause for the slightly increased MMP in the presence of HNE. However, DEAB without HNE already had a strong effect on MMP, reducing it by $\sim 44 \%$ (Figure 4B). Surprisingly, pre-incubation with DEAB also strongly increased the uncoupling effect of the artificial uncoupler CCCP in cells fed with glutamine (Figure 4B). Since CCCP is very unlikely related to the activity of the ALDH, it is possible that DEAB not only affects the activity of the ALDH, but also the stability of the mitochondrial membrane, which questions previous experiments with DEAB. Because it was difficult to conclude from these results, to what extent $\beta$-oxidation of HNE plays a role in maintaining MMP, we tested which difference between cells in glucose and glutamine medium could lead to a different capacity to $\beta$-oxidize HNE. Since the ALDH needs NAD ${ }^{+}$for the oxidation of HNE to HNA, we suggested that different $\mathrm{NAD}^{+}$levels between cells in glucose and glutamine media lead to different ALDH activity and thus different $\beta$-oxidation of HNE. Indeed, two-photon imaging revealed, that $\mathrm{NADH}$ fluorescence is roughly twice as high after $2 \mathrm{~h}$ 30 min starvation in $25 \mathrm{mM}$ glucose medium compared to glutamine medium (Figure 4C), which corresponds to low $\mathrm{NAD}^{+}$levels and thus potentially low ALDH activity. NADH levels in medium containing both glucose and glutamine were slightly lower than in medium 
A

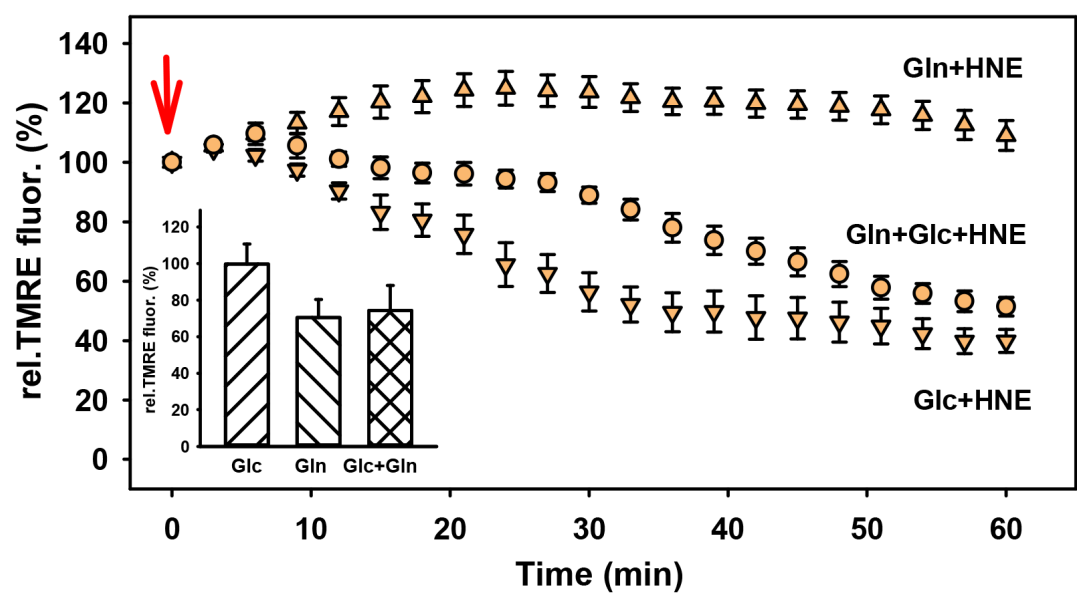

B

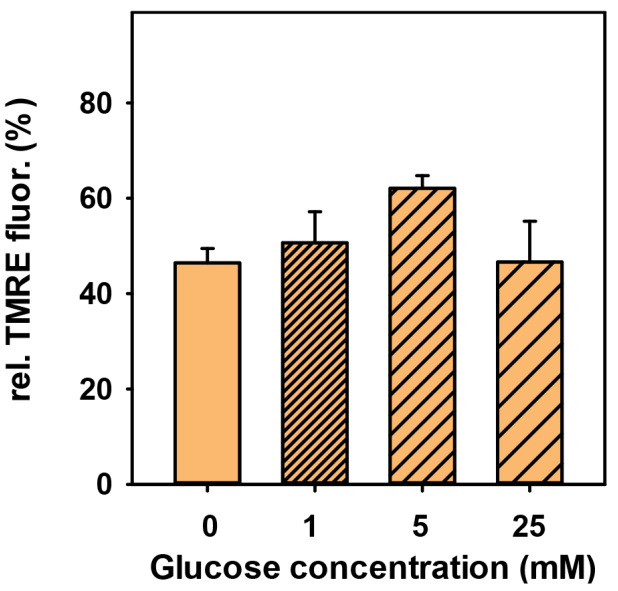

C

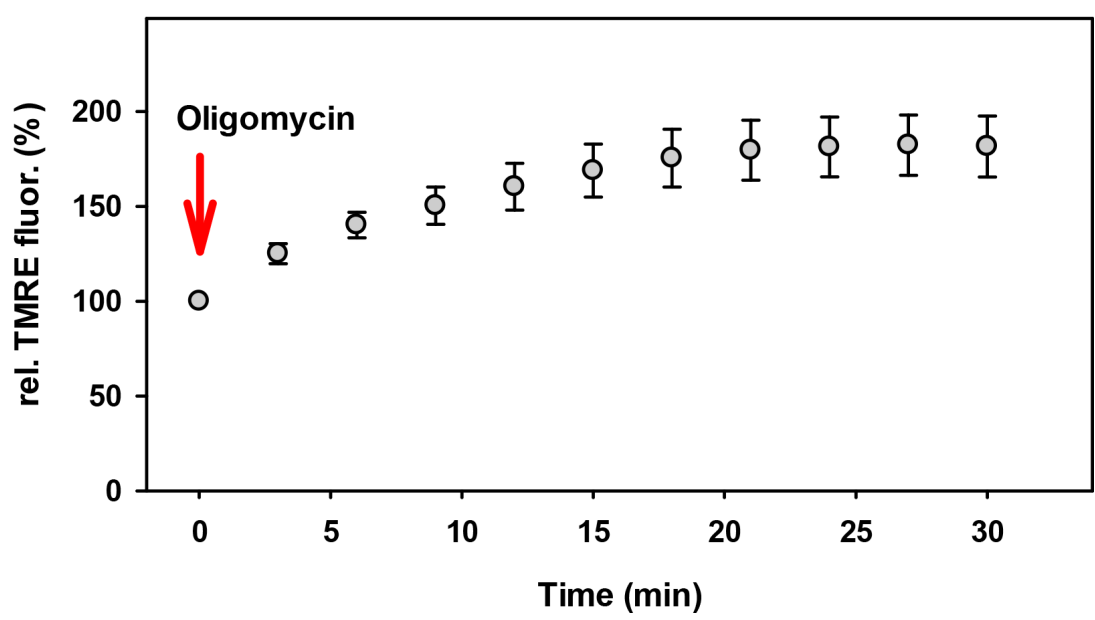

Figure 3: Dependence of the HNE-induced mitochondrial membrane potential alteration of N18TG2 cells on nutrient supply. A. DMEM medium contained $25 \mathrm{mM}$ glucose (down-pointing triangles; Glc), $3.85 \mathrm{mM}$ glutamine (up-pointing triangles; Gln) or $24.5 \mathrm{mM}$ glucose $+3.85 \mathrm{mM}$ glutamine (circles; Gln+Glc). TMRE fluorescence in the presence of HNE was normalized to the TMRE fluorescence without HNE (insert). The concentration of HNE (arrow indicates the addition) was $16 \mu \mathrm{M}$. Data are presented as mean values \pm SEM for 5-10 independent experiments. B. TMRE-stained cells were incubated for $2 \mathrm{~h} 30 \mathrm{~min}$ in DMEM medium with different glucose concentrations before addition of $16 \mu \mathrm{M}$ HNE. TMRE fluorescence after $1 \mathrm{~h}$ HNE treatment normalized to the fluorescence before HNE addition is shown. Data are presented as mean values \pm SEM for 3 independent experiments. C. TMRE stained cells were starved for $2 \mathrm{~h}$ $30 \mathrm{~min}$ in $3.85 \mathrm{mM}$ glutamine medium. TMRE fluorescence after addition of $2 \mu \mathrm{M}$ oligomycin was normalized to the fluorescence without oligomycin. Data are presented as mean values \pm SEM for 4 independent experiments. 
A

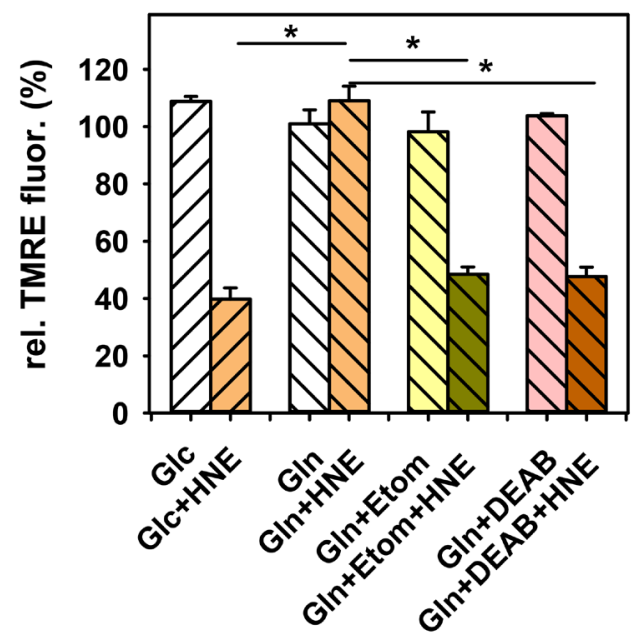

B
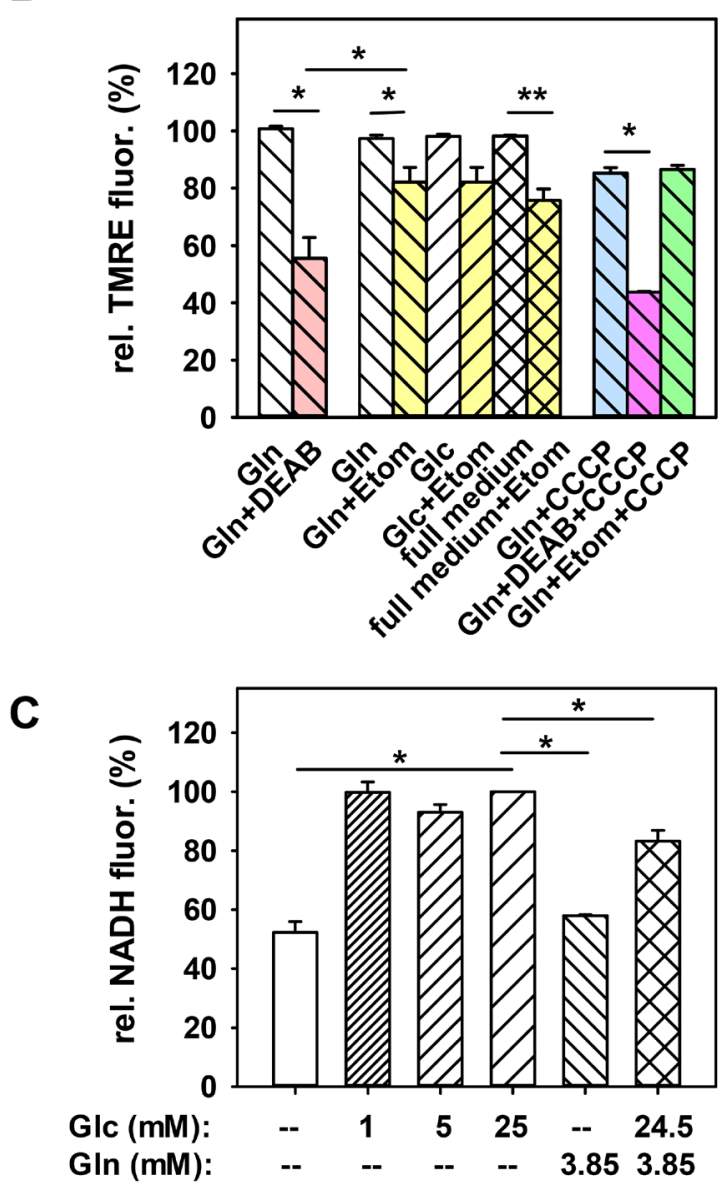

Figure 4: Dependence of the HNE-induced mitochondrial membrane potential alteration of N18TG2 cells on $\boldsymbol{\beta}$-oxidation. A. In cells, incubated in $3.85 \mathrm{mM}$ glutamine medium (Gln), either $\beta$-oxidation was inhibited with $100 \mu \mathrm{M}$ etomoxir (Etom), or ALDH activity was blocked with $50 \mu \mathrm{M}$ DEAB. Then $16 \mu \mathrm{M}$ HNE was added for $1 \mathrm{~h}$. TMRE fluorescence after $1 \mathrm{~h}$ incubation with HNE was normalized to the fluorescence before HNE addition. For comparison controls without inhibitors are shown ( $25 \mathrm{mM}$ glucose medium (Glc) or Gln). Data are presented as mean values \pm SEM for 3-10 independent experiments. B. Effect of etomoxir (Gln + Etom), DEAB $(\mathrm{Gln}+\mathrm{DEAB})$ and $1 \mu \mathrm{M} \mathrm{CCCP}$ on the MMP of cells in glutamine medium without HNE. Etomoxir was also added to full medium (full medium+Etom) and to cells incubated in glucose medium (Glc+Etom). White bars are controls without inhibitor. Data are presented as mean values \pm SEM for 3-12 independent experiments. C. NADH levels of cells incubated in medium containing different glucose (Glc) or glutamine (Gln) concentrations. NADH fluorescence was normalized to NADH fluorescence of cells incubated $2 \mathrm{~h} 30 \mathrm{~min}$ in $25 \mathrm{mM}$ glucose medium. Data are presented as mean values \pm SEM for 200 cells from 2 independent experiments. ${ }^{*} \mathrm{p}<0.05$, $* *$ p $<0.01$. 
containing only glucose. NADH levels in cells kept in $1 \mathrm{mM}$ or $5 \mathrm{mM}$ glucose were similar to those in cells kept in $25 \mathrm{mM}$ glucose (Figure 4C), which would be in line with the MMP results after HNE treatment (Figure 3B). However, cells incubated in DMEM medium without any additional nutrients, which were not able to maintain their MMP after HNE treatment (Figure 3B), had similar low $\mathrm{NADH}$ levels as cells in glutamine medium (Figure 4C). Thus, a correlation between low NADH levels and the ability to maintain the MMP is hardly probable. Next, we directly tested the ALDH activity with the AldeRed ALDH detection assay [53]. Interestingly, the fluorescence and thus ALDH activity was significantly higher in cells with glucose medium compared to cells with glutamine medium (Figure 5), despite the lower NAD ${ }^{+}$levels. Thus it is unlikely, that cells in glutamine medium exhibit a higher $\beta$-oxidation of HNE to maintain MMP.

\section{Cells fed with glutamine sustain MMP after addition of HNE via fatty acid $\beta$-oxidation}

As a next step, we tested whether $\beta$-oxidation of fatty acids is the cause for the maintained MMP, since $\beta$-oxidation is typically up-regulated in starved cells without glucose [54]. To test this, we blocked $\beta$-oxidation in cells with glutamine medium with etomoxir before HNE treatment. It has been shown that incubation with etomoxir, which is an irreversible inhibitor of carnitine palmitoyltransferase- 1 in the outer mitochondrial membrane, reduces production of ATP due to inhibition of $\beta$-oxidation [55]. It is important to mention, that the carnitine palmitoyltransferase system transports long chain fatty acids (LCFA, C12-C20), while fatty acids with shorter chains can diffuse passively over the mitochondrial membrane and get converted by the medium chain acylCoA dehydrogenase for subsequent $\beta$-oxidation. Thus, etomoxir should not influence $\beta$-oxidation of HNA (C9). To exclude the additional toxicity of etomoxir which reduces GSH and NADPH levels at high concentrations (1 mM, [56, 57]), we used a relatively low concentration of $100 \mu \mathrm{M}$, previously shown to be safe in human glioblastoma SF188 cells [56]. Addition of $100 \mu \mathrm{M}$ etomoxir to cells in glutamine medium without HNE reduced MMP by $\sim 20 \%$ after 30 minutes, similar to results with cells in glucose or full medium (Figure 4C). This indicates that at this time point, $\beta$-oxidation of fatty acids is not significantly up-regulated in cells incubated in glutamine medium. In this regard, it was now surprising that cells treated with etomoxir in glutamine medium could no longer maintain their MMP after addition of HNE, and the decrease in MMP was similar to that observed in experiments with cells in glucose medium (Figure 4B). It means that cells fed with glutamine without glucose increased the $\beta$-oxidation of fatty acids only during an increased stress situation such as the rise of HNE levels. We tested, whether pre-incubation with etomoxir would alter CCCP uncoupling in cells fed with glutamine, which was not the case (Figure 4C). Thus, we conclude that $\beta$-oxidation of fatty acids, but not of HNE, is the likely cause for the maintained MMP after HNE treatment in cells incubated in glutamine medium.

\section{Cell viability after HNE treatment differs between glutamine- and glucose-fed cells}

HNE treatment led to a strong stress response in N18TG2 cells (Figure 1). Interestingly, the morphology of the cells was very different after $1 \mathrm{~h}$ HNE treatment between cells in glucose and glutamine medium, especially regarding the nucleus (Figure 6A-6B). In cells fed with glutamine as a main nutrient, the volume ratio between cytosol to nucleus remained unchanged after treatment with HNE. In cells kept in glucose medium, the nucleus filled the major portion of the cell volume, which was confirmed by DAPI staining (Figure 6I). The morphological change of HNE-treated cells in glucose medium cannot be attributed to the MMP decrease, since cells in full medium and in medium containing both glucose and glutamine, which exhibit a loss of MMP (Figure 1D; Figure 3A), had a morphology similar to cells kept in glutamine (Figure 6C-6D) after HNE treatment. This indicates that a lack of glutamine may be the cause for the morphological change. We further analysed cellular survival by staining cells with propidium iodide (PI). We found an increased percentage of dead cells after $1 \mathrm{~h}$ HNE treatment with glucose medium compared to glutamine medium (Figure 6G). Also the increased caspase 3 activity in HNE-treated cells (Figure 6G) confirmed the higher cell apoptosis in glucose medium compared to glutamine medium.

To evaluate whether the cells would recover from the severe HNE treatment, we washed the cells after 1 $\mathrm{h}$ HNE treatment, and incubated them for $3 \mathrm{~h}$ in fresh full medium, before determining MMP. Cells treated in glucose media could not recover their low MMP in contrast to the cells in glutamine whose MMP was roughly double as high as in the cells treated in glucose media after $3 \mathrm{~h}$ recovery (Figure $6 \mathrm{E}-6 \mathrm{~F}$ ). Even if observed one day after HNE treatment, cells treated in glutamine media still exhibited a distinct TMRE fluorescence, which could not be observed in glucose-fed cells.

It is generally accepted that HNE acts on cells differently dependent on its concentration (s. Introduction) and cell type. For example, it has been shown, that HNE induces apoptosis via inactivation of membrane-associated catalase in cancer cells but not in normal cells [58]. However, at lower concentrations, HNE can act as a cell signalling molecule to alter several cellular functions such as increasing cellular survival against oxidative stress or it can impact cell differentiation, cell cycle, cell growth or cellular metabolism. Our results show, that the toxicity of HNE is dependent on the metabolic state of cancer cells 
and HNE can also induce cellular signalling to enhance cell survival by increasing cellular $\beta$-oxidation even at high toxic HNE concentrations, but only if just glutamine is present as a nutrient.

Our results differ considerably from those observed previously in SH-SY5Y neuroblastoma cells [38]. Dodson et al. showed that after starvation, HNE induced an increased cell death and strongly reduced MMP, while the effects without starvation were very weak. This discrepancy could be explained by three main differences in the experimental system employed. (i) Most importantly, Dodson et al. deprived glucose by blocking glycolysis with 2-deoxyglucose or koningic acid, which inhibits the autophagic flux and thus drastically increases HNE toxicity; (ii) differentiated neuroblastoma cells were used in experiments, where metabolism was different compared to undifferentiated cells [59]; and iii) cells were starved for 24 hours compared to $2 \mathrm{~h} 30 \mathrm{~min}$ starvation applied in our experiments.

\section{4-oxo-2-nonenal acts stronger than HNE, but the difference between glucose- and glutamine-fed cells is strongly diminished}

Finally, we tested whether these results are specific for $\mathrm{HNE}$ or whether reactive aldehydes known to be more toxic behave similarly. For this we determined the effect of 4-oxo-2-nonenal (ONE) on the MMP under different and the same starvation conditions as for HNE. Indeed, we found that $\sim 0.75-1 \mu \mathrm{M}$ ONE had roughly the same effect on the MMP as $16 \mu \mathrm{M}$ HNE in medium with both glucose and glutamine (Figure 7). Next, we tested the difference in MMP alteration between cells kept in glucose and glutamine media after ONE treatment. Figure 7 shows that while in glutamine medium, the cells could maintain their MMP for $1 \mathrm{~h}$ in the presence of $0.75 \mu \mathrm{M}$ ONE, the MMP in cells kept in glucose media were reduced by $\sim 25 \%$. Remarkably, this difference between both media was much smaller compared to HNE (25\% against $65 \%$ ). MMP never increased above $100 \%$ in glutamine-fed cells, which is also in contrast to HNE. Blocking $\beta$-oxidation with etomoxir in cells kept in glutamine medium led to a reduction of the MMP closer to the levels of cells with glucose, although not reaching the same levels. Preincubation with DEAB did not alter the effect of ONE on the MMP in cells incubated in glutamine medium in contrast to the results observed with HNE. An explanation for these results might be the differences in interaction of HNE and ONE with membranes by formation of various adducts, which may have a different impact on metabolic pathways [12].

\section{CONCLUSION}

In summary, our results show that HNE's effect on cancer cells depends on the type of nutrient deprivation used (Figure 8). Under conditions of glucose deprivation, where the cells still have glutamine, cancer cells can adapt to oxidative stress induced by incubation with HNE by increasing $\beta$-oxidation of fatty acids. This allows cells to maintain their MMP for a prolonged period in contrast to cells in glucose medium deprived of glutamine, where the MMP was severely reduced due to HNE addition. However, HNE strongly reduced MMP even in media,
A

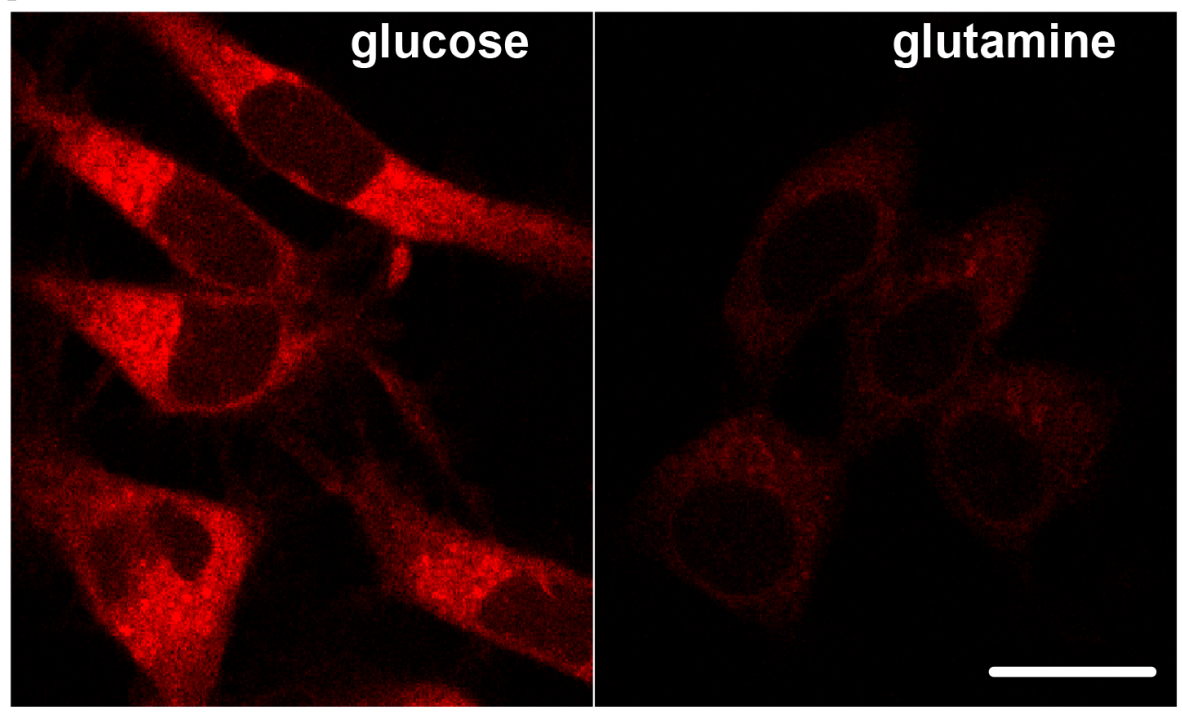

B

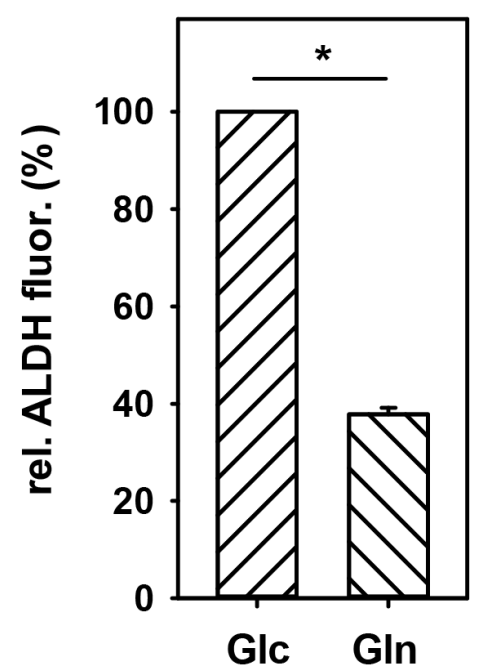

Figure 5: Nutrient dependence of AldeRed fluorescence in N18TG2 cells. A. Typical fluorescence images of cells stained for $30 \mathrm{~min}$ with AldeRed after $2 \mathrm{~h} 30 \mathrm{~min}$ incubation in $25 \mathrm{mM}$ glucose (left) or $3.85 \mathrm{mM}$ glutamine (right) medium. Scale bar is $20 \mu \mathrm{m}$. B. Comparison of the relative AldeRed fluorescence changes in cells incubated in glucose (Glc) or glutamine (Gln) medium. Measured ALDH fluorescence was normalized to ALDH fluorescence of cells incubated in glucose medium. Data are presented as mean values \pm SEM for 2 independent experiments, ( $>600$ cells analyzed). ${ }^{*} \mathrm{p}<0.05$. 
Glc

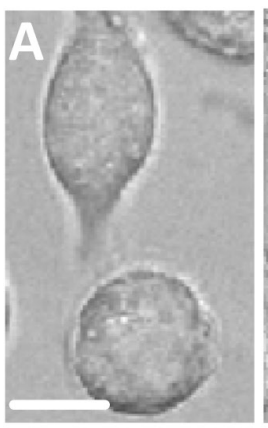

Glc+TMRE
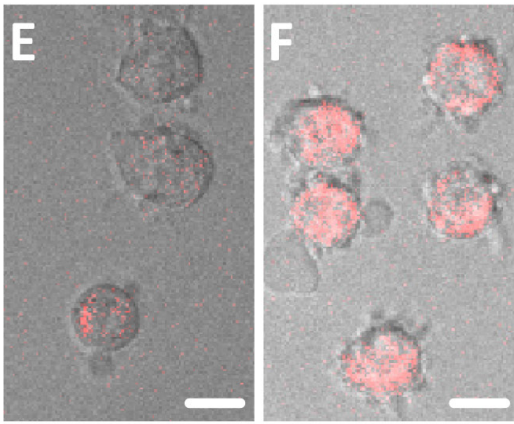

Full medium

\section{GIc+GIn}
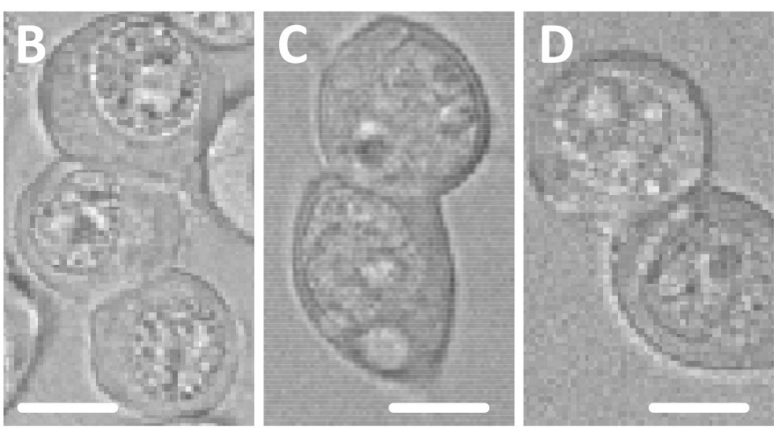

$\mathbf{G}$
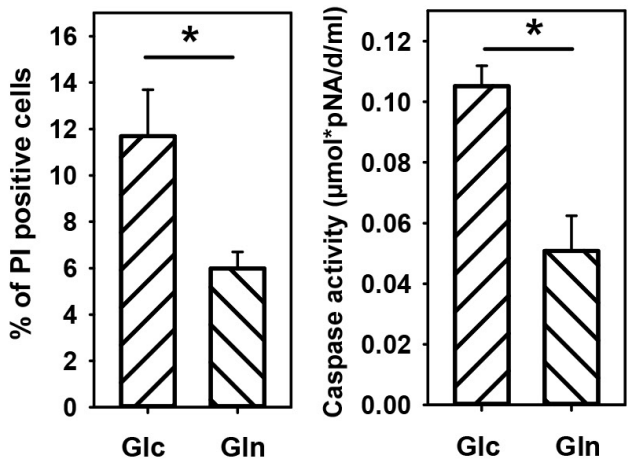
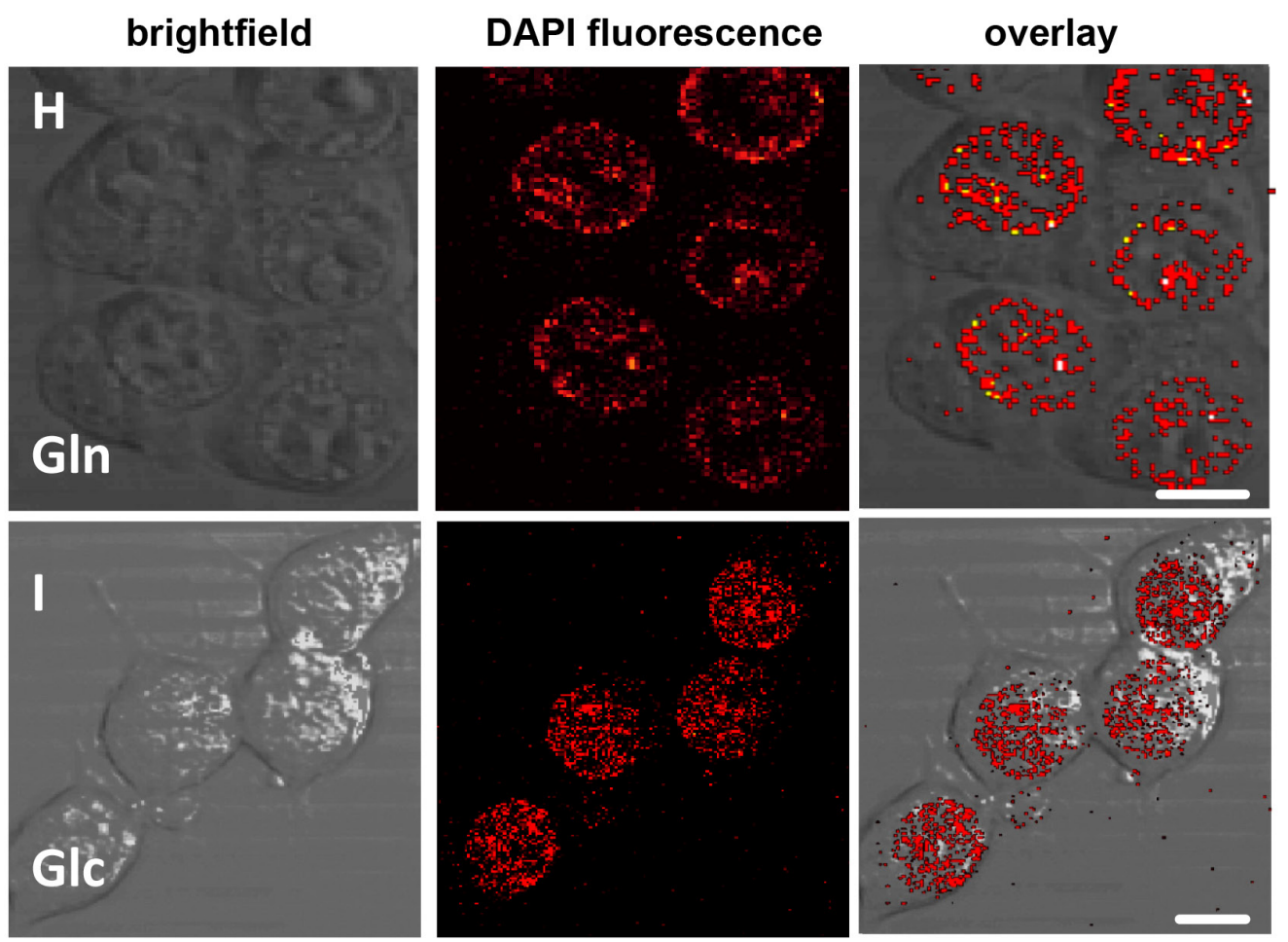

Figure 6: Morphology, viability and nucleus morphology of cells incubated in different media after addition of HNE observed with brightfield and fluorescent microscopy. Cells were incubated for $150 \mathrm{~min}$ in medium containing either A., E. and I. $25 \mathrm{mM}$ glucose, or B., F. and H. $3.85 \mathrm{mM}$ glutamine medium, or C. full medium, or D. $24.5 \mathrm{mM}$ glucose and $3.85 \mathrm{mM}$ glutamine. The concentration of HNE added for $1 \mathrm{~h}$ was $16 \mu \mathrm{M}$. A-D. Morphology, $\mathbf{E}$ and $\mathbf{F}$. Reversibility of the mitochondrial membrane potential: cells were washed after HNE treatment and incubated for 3 hours in fresh medium with TMRE. G. Viability: The percentage of propidium iodide (PI) positive cells and caspase 3 activity was determined after $1 \mathrm{~h}$ incubation with HNE. Data are presented as mean values \pm SEM for 5 independent experiments. * $\mathrm{p}<0.05$. H and I. Cell nuclei were stained with DAPI. Scale bar is $10 \mu \mathrm{m}$. 


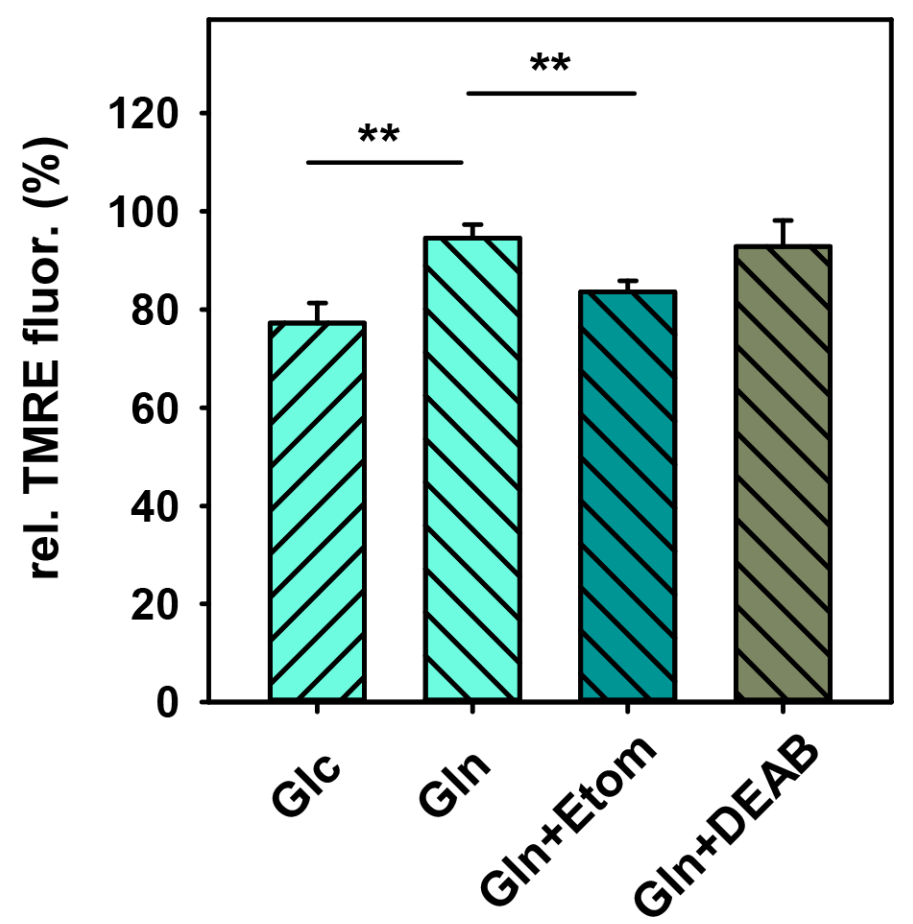

Figure 7: Effect of 4-oxo-2-nonenal (ONE) on alteration of mitochondrial membrane potential. Cells were stained with TMRE and incubated for $2 \mathrm{~h} 30 \mathrm{~min}$ in $25 \mathrm{mM}$ glucose medium (Glc), $3.85 \mathrm{mM}$ glutamine medium (Gln), $50 \mu \mathrm{M} \mathrm{DEAB}+3.85 \mathrm{mM}$ glutamine medium (Gln+DEAB) or $100 \mu \mathrm{M}$ etomoxir $+3.85 \mathrm{mM}$ glutamine medium (Gln+Etom) before $0.75 \mu \mathrm{M}$ ONE was added. DEAB or etomoxir were added to the cells 75 or $120 \mathrm{~min}$ after the start of starvation. The TMRE fluorescence after $1 \mathrm{~h}$ incubation with ONE was normalized to the fluorescence before ONE addition. Data are presented as mean values \pm SEM for 8-13 independent experiments. $* * \mathrm{p}<0.01$.

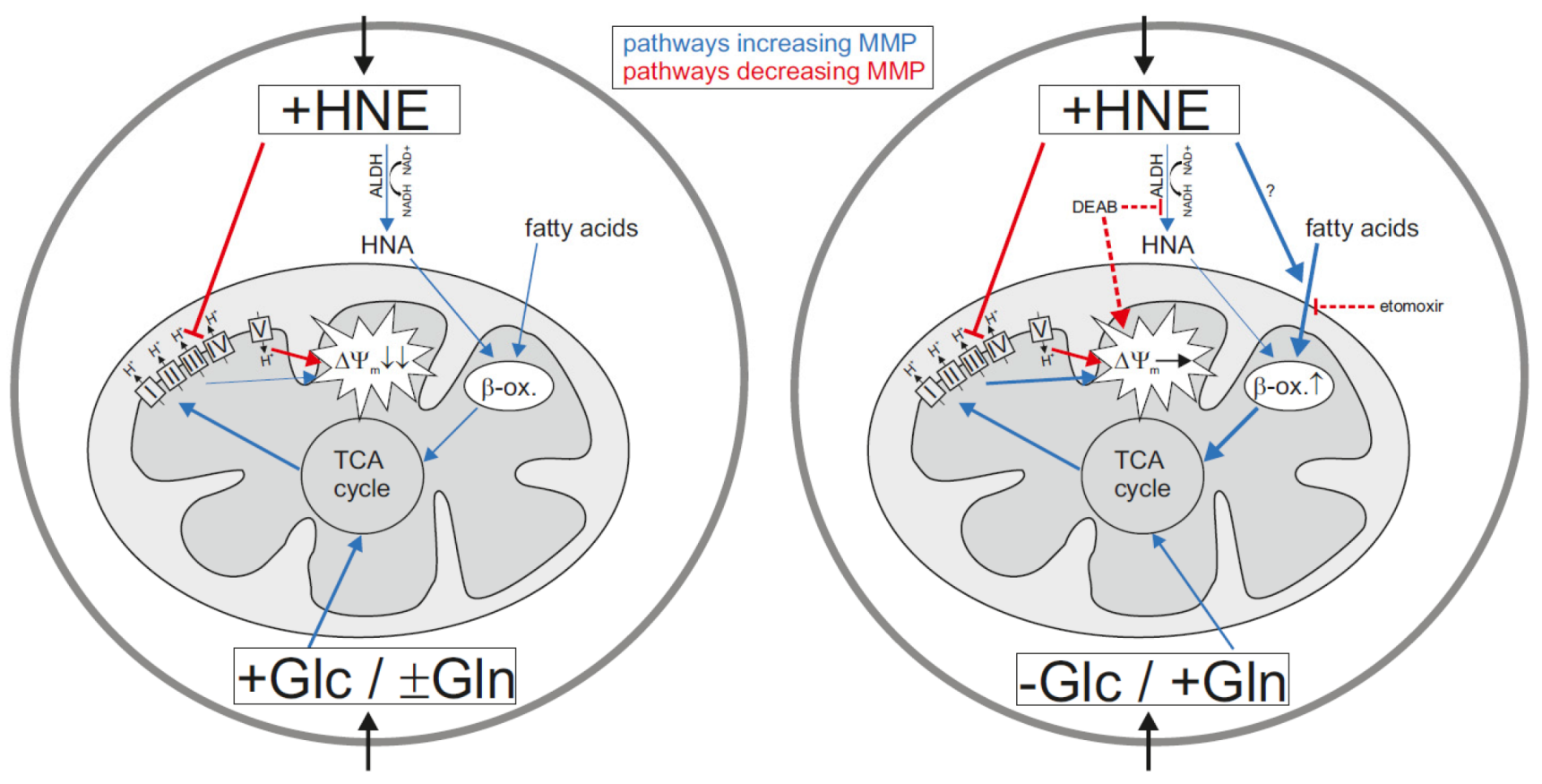

Figure 8: Mechanism of the HNE-induced alteration of mitochondrial membrane potential (MMP) in nutrientdeprived cancer cells. Left: Cancer cells in glucose medium with or without glutamine. Right: Cancer cells in glutamine medium. In red are pathways leading to a reduction of MMP, in blue MMP increasing pathways. Thick lines indicate pathway activation. Dashed lines indicate the effects of the inhibitors DEAB and etomoxir. 
where both glucose and glutamine were present, indicating that in order to maintain the MMP via $\beta$-oxidation, cells have to be deprived of glucose and glutamine must be present. Cell viability results show that the cells in glutamine medium exhibited a markedly better cell survival against HNE toxicity compared to cells in glucose medium. Our work gives further mechanistic insights into oxidative stress in nutrient-deprived cancer cells, which could improve anti-cancer treatments based on nutrient deprivation.

\section{MATERIALS AND METHODS}

\section{Chemicals}

TMRE (tetramethyl rhodamine ethyl ester), DEAB (diethylaminobenzaldehyde), etomoxir, rotenone, antimycin A, TTFA (thenoyltrifluoroacetone), sodium azide and oligomycin were purchased from Sigma Aldrich. DAPI were purchased from Cell Signaling Technology ${ }^{\circledR}$, propidium iodide (PI) from Invitrogen. HNE and ONE, dissolved in ethanol, were either obtained from Cayman Chemicals, or produced by ourselves (see below).

\section{Synthesis of (E)-4-hydroxy-2-nonenal (4-HNE)}

1-Octen-3-ol (153 $\mu \mathrm{L}, 1.0 \mathrm{mM}, 1.0$ equiv) was dissolved in $5 \mathrm{~mL}$ of dry dichloromethane under argon atmosphere and the mixture degassed. Then acrolein (223 $\mu \mathrm{L}, 3.0 \mathrm{mM}, 3.0$ equiv) was added, followed by $1.25 \mathrm{~mol} \%$ of Grubbs-Hoveyda $2^{\text {nd }}$ generation catalyst. The reaction was stirred at RT and after $3 \mathrm{~h}$ another $1.25 \mathrm{~mol} \%$ of catalyst was added (total $16 \mathrm{mg}, 0.025$ $\mathrm{mM}, 0.025$ equiv). The reaction mixture was further stirred for $15 \mathrm{~h}$ and evaporated. The crude product was purified by flash chromatography on silica using ethylacetate:hexane = 1:2 as eluent yielding $144 \mathrm{mg}(92 \%)$ of product. All spectroscopic data for 4-HNE were in accordance with the previously reported [60] and were as follows for ${ }^{1} \mathrm{H} \mathrm{NMR}\left(\mathrm{CDCl}_{3}\right): \delta 0.91(\mathrm{t}, J=7.0 \mathrm{~Hz}, 3 \mathrm{H})$, $1.26-1.44(\mathrm{~m}, 6 \mathrm{H}), 1.61-1.69(\mathrm{~m}, 2 \mathrm{H}), 1.83(\mathrm{~d}, J=4.5$ $\mathrm{Hz}, 1 \mathrm{H}), 4.45$ (m 1H), 6.32 (ddd, $J=1.5,7.9$ and $15.9 \mathrm{~Hz}$, $1 \mathrm{H}), 6.83$ (dd, $J=4.5,15.9,1 \mathrm{H}), 9.6$ (d, $J=7.9 \mathrm{~Hz}, 1 \mathrm{H})$.

\section{Synthesis of (E)-4-oxo-2-nonenal (4-ONE)}

4-hydroxynonenal (19 mg, $0.12 \mathrm{mM}, 1.0$ equiv) was dissolved in $1 \mathrm{~mL}$ of dry dichloromethane under argon atmosphere. The mixture was cooled to $0{ }^{\circ} \mathrm{C}$ and the DessMartin oxidant (62 mg, $0.15 \mathrm{mM}, 1.2$ equiv) was added. The reaction mixture was further stirred at $0{ }^{\circ} \mathrm{C}$ for $1 \mathrm{~h}$, diluted with dichloromethane and washed with saturated $\mathrm{NaHCO}_{3}$ (aq). The organic layer was separated, dried on $\mathrm{Na}_{2} \mathrm{SO}_{4}$ and evaporated. The crude product was purified by flash chromatography on silica using ethyl-acetate:hexane $=1: 2$ as eluent yielding $15 \mathrm{mg}(80 \%)$ of product. All spectroscopic data for 4-ONE were in accordance with the previously reported $[61,62]$ and were as follows for ${ }^{1} \mathrm{H} \mathrm{NMR}\left(\mathrm{CDCl}_{3}\right): \delta 0.91(\mathrm{t}, J=6.9 \mathrm{~Hz}, 3 \mathrm{H}), 1.26-1.35$ (m, 4H), 1.55-1.72 (m, 2H), 2.69 (t, J=7.3 Hz, 2H), 6.77 $(\mathrm{dd}, J=6.9$ and $16.5 \mathrm{~Hz}, 1 \mathrm{H}), 6.88(\mathrm{~d}, J=16.2 \mathrm{~Hz}, 1 \mathrm{H})$, $9.78(\mathrm{~d}, J=7.2 \mathrm{~Hz}, 1 \mathrm{H})$.

\section{Cell culture}

N18TG2 cells (Deutsche Sammlung von Mikroorganismen \& Zellkultur GmbH (DSMZ), Braunschweig, Germany) were cultivated at $37^{\circ} \mathrm{C}$ and $5 \% \mathrm{CO}_{2}$. Cell culture media contained DMEM $(21.6 \mathrm{mM}$ glucose) supplemented with $9.6 \%$ fetal bovine serum, 3.85 $\mathrm{mM}$ glutamine and $1.92 \mathrm{mM}$ sodium pyruvate (all obtained from Sigma-Aldrich). For experiments cells were cultivated in 4-well Petri dishes (Greiner Bio-One, Germany), coated with poly-D-lysine (Sigma-Aldrich) with $0.5 \mathrm{ml}$ medium per well for 24-72 $\mathrm{h}$ before the start of the measurements.

\section{Microscopy}

TMRE was excited at a wavelength of $561 \mathrm{~nm}$ with a DPPS laser. Fluorescence was measured with an inverse confocal laser scanning microscope (Leica TCS SP5 II). The microscope was equipped with a heating box for $37^{\circ} \mathrm{C}$ and $5 \% \mathrm{CO}_{2}$ supply allowing long-term measurements with living cells. Fluorescence was collected through a $63 \mathrm{X}$ water or $40 \mathrm{X}$ oil immersion objective in an emission channel of $570-690 \mathrm{~nm}$. Z-stacks of cells with a step size of $500 \mathrm{~nm}(256 \times 256$ pixels; $400 \mathrm{~Hz} ; 73$ frames per z-stack) were recorded every 3 minutes for typically one hour. PI was excited with $514 \mathrm{~nm}$ and detected in a 550 $-690 \mathrm{~nm}$ channel. NADH levels were imaged with two photon microscopy at an excitation wavelength of $740 \mathrm{~nm}$ (emission channel: 400-530 nm) with Chameleon Vision-S laser (Coherent). DAPI fluorescence was imaged after excitation at $700 \mathrm{~nm}$ and detected in an emission channel of $400-480 \mathrm{~nm}$.

\section{Measurements of aldehyde dehydrogenase activity}

ALDH activity was determined with the AldeRed ALDH detection assay (Merck Millipore) according to the manufacturer's instruction, which is also described in [53]. Briefly, verapamil was dissolved in PBS and added as a 1:100 dilution to the cells (final concentration 24.6 $\mu \mathrm{g} / \mathrm{ml}$ ). AldeRed 588-A was added in a 1:200 dilution to the verapamil treated cells for $30 \mathrm{~min}$. Cells pre-treated with DEAB solution (dilution 1:100, final concentration $15 \mu \mathrm{M})$ were used as a control.

\section{Cell viability}

For cell viability measurements, cells were starved for $2 \mathrm{~h} 30 \mathrm{~min}$ in $25 \mathrm{mM}$ glucose or $3.85 \mathrm{mM}$ 
glutamine media, and then $16 \mu \mathrm{M}$ HNE was added for 1 h. Subsequently cells were washed three times. For DAPI staining, cells were fixed in $4 \%$ paraformaldehyde and washed again two times. Then cells were stained with 0.6 $\mu \mathrm{M}$ DAPI dissolved in PBS for 5 min and subsequently washed three times for $5 \mathrm{~min}$ before analyzing DAPI fluorescence with a fluorescence microscope. For measurements with propidium iodide (PI) cells were stained for 5 min with $1.5 \mu \mathrm{M}$ PI dissolved in PBS. After washing, PI fluorescence was analyzed with fluorescence microscopy. For the recovery measurements, cells were incubated for three hours in fresh full medium containing $12.5 \mathrm{nM}$ TMRE, before analyzing TMRE fluorescence via fluorescence microscopy.

Caspase-3 activity in N18TG2 neuroblastoma cells was measured using the caspase- 3 colorimetric assay kit (Sigma-Aldrich). Cells were exposed to $25 \mathrm{mM}$ glucose or $3.85 \mathrm{mM}$ glutamine containing media for $2 \mathrm{~h} 30$ min, followed by incubation with HNE ( $1 \mathrm{~h})$. In control experiments cells were maintained in glucose or glutamine media for $3.5 \mathrm{~h}$. After that, cell pellets were centrifuged at $750 \mathrm{~g} / 4^{\circ} \mathrm{C}$ for $6 \mathrm{~min}$ and resuspended in $100 \mu \mathrm{l}$ of lysis buffer containing $10 \mathrm{mM}$ HEPES, $\mathrm{pH}$ 7.4, 1 mM CHAPS, $1 \mathrm{mM}$ DTT. Cell lysates were centrifuged again (12000 g for $1.5 \mathrm{~min}$ ) and $45 \mu \mathrm{l}$ of supernatant supplemented with $55 \mu \mathrm{l}$ assay buffer (containing $2 \mathrm{mM}$ HEPES, pH 7.4, 0.2 mM EDTA, $0.16 \mathrm{mM}$ CHAPS, and $0.5 \mathrm{mM}$ DTT) were filled in 96-well plates per well in duplicates. To one of the wells, the selective caspase 3 inhibitor N-acetylAsp-Glu-Val-Asp-CHO $(20 \mu \mathrm{M})$ was added to record a nonspecific signal. Afterwards, cell lysates were incubated with $\mathrm{N}$-acetyl-Asp-Glu- Val-Asp p-nitroaniline (0.2 mM) for $24 \mathrm{~h}$ at $37^{\circ} \mathrm{C}$, and the generation of p-nitroaniline (pNA) was measured at $405 \mathrm{~nm}$ in a microtiter plate reader. The enzyme activity $(\mu \mathrm{M} \mathrm{pNA} / \mathrm{d} / \mathrm{ml})$ was calculated as the $\left(\mathrm{OD}_{\text {sample }}-\mathrm{OD}_{\text {sample+inhibitor }}\right) / 10.5 \times 0.045$, with $10.5=\varepsilon^{\mathrm{mM}}$ p-nitroaniline. For determination of $\mathrm{HNE}$ induced caspase 3 activity, the ODs of the corresponding controls without HNE treatment were subtracted from the ODs with HNE treatment.

\section{Data analysis}

Images were analysed with Leica LAS AF Lite software. Fluorescence levels in cells were corrected for the background. All data are presented as mean \pm SEM. p-values were determined with a two sample t-test with unequal variances and classified with $* \mathrm{p}<0.05$, ** $\mathrm{p}<$ $0.01, * * * \mathrm{p}<0.001$.

\section{Abbreviations}

ALDH, aldehyde dehydrogenase; CCCP, Carbonyl cyanide m-chlorophenyl hydrazone; DEAB, diethylaminobenzaldehyde; DMEM, Dulbecco's Modified Eagle Medium; LCFA, long chain fatty acids; MMP, mitochondrial membrane potential; HNA, 4-hydroxy2-nonenoic acid; HNE, 4-hydroxy-2-nonenal (HNE); ONE, 4-oxo-2-nonenal; PI, propidium iodide; PUFAs, polyunsaturated fatty acids; TMRE, tetramethyl rhodamine ethyl ester; TTFA, thenoyltrifluoroacetone.

\section{ACKNOWLEDGMENTS}

The authors are grateful to COST Action CM1201 Biomimetic Radical Chemistry for the scientific exchange and cooperation. We thank Quentina Beatty as a native English speaker and Caroline Nake for editorial assistance.

\section{CONFLICTS OF INTEREST}

The authors declare that they have no competing financial interest.

\section{FUNDING}

This work was supported by the Austrian Research Fund (FWF, P25123 to E.P.) and Croatian Science Foundation (UIP-2014-09-6090 to KV).

\section{REFERENCES}

1. Holmstrom KM, Finkel T. Cellular mechanisms and physiological consequences of redox-dependent signalling. Nat Rev Mol Cell Biol. 2014; 15:411-421.

2. Cadenas E, Davies KJ. Mitochondrial free radical generation, oxidative stress, and aging. Free Radic Biol Med. 2000; 29:222-230.

3. Angelova PR, Abramov AY. Functional role of mitochondrial reactive oxygen species in physiology. Free Radical Biology and Medicine.

4. Catala A. Lipid peroxidation of membrane phospholipids generates hydroxy-alkenals and oxidized phospholipids active in physiological and/or pathological conditions. ChemPhysLipids. 2009; 157:1-11.

5. Lin D, Lee HG, Liu Q, Perry G, Smith MA, Sayre LM. 4-Oxo-2-nonenal is both more neurotoxic and more protein reactive than 4-hydroxy-2-nonenal. ChemResToxicol. 2005; 18:1219-1231.

6. Yin $\mathrm{H}, \mathrm{Zhu}$ M. Free radical oxidation of cardiolipin: chemical mechanisms, detection and implication in apoptosis, mitochondrial dysfunction and human diseases. Free Radic Res. 2012; 46:959-974.

7. Esterbauer H, Koller E, Slee RG, Koster JF. Possible involvement of the lipid-peroxidation product 4-hydroxynonenal in the formation of fluorescent chromolipids. Biochem J. 1986; 239:405-409. 
8. Doorn JA, Petersen DR. Covalent adduction of nucleophilic amino acids by 4-hydroxynonenal and 4-oxononenal. ChemBiolInteract. 2003; 143-144:93-100.

9. Malingriaux EA, Rupprecht A, Gille L, Jovanovic O, Jezek P, Jaburek M, Pohl EE. Fatty Acids are Key in 4-Hydroxy2-Nonenal-Mediated Activation of Uncoupling Proteins 1 and 2. PLoSONE. 2013; 8:e77786.

10. Guichardant M, Taibi-Tronche P, Fay LB, Lagarde M. Covalent modifications of aminophospholipids by 4-hydroxynonenal. Free RadicBiolMed. 1998; 25:1049-1056.

11. Sayre LM, Lin D, Yuan Q, Zhu X, Tang X. Protein adducts generated from products of lipid oxidation: focus on HNE and one. Drug Metab Rev. 2006; 38:651-675.

12. Jovanovic O, Pashkovskaya AA, Annibal A, Vazdar M, Burchardt N, Sansone A, Gille L, Fedorova M, Ferreri C, Pohl EE. The molecular mechanism behind reactive aldehyde action on transmembrane translocations of proton and potassium ions. Free Radical Biology and Medicine. 2015; 89:1067-1076.

13. Strohmaier H, Hinghoferszalkay H, Schaur RJ. Detection of 4-Hydroxynonenal (Hne) as a Physiological Component in Human Plasma. J Lipid Mediat Cell. 1995; 11:51-61.

14. Milkovic L, Cipak Gasparovic A, Zarkovic N. Overview on major lipid peroxidation bioactive factor 4-hydroxynonenal as pluripotent growth-regulating factor. Free Radic Res. 2015; 49:850-860.

15. Ishii T, Itoh K, Ruiz E, Leake DS, Unoki H, Yamamoto M, Mann GE. Role of Nrf2 in the regulation of CD36 and stress protein expression in murine macrophages: activation by oxidatively modified LDL and 4-hydroxynonenal. Circ Res. 2004; 94:609-616.

16. Chapple SJ, Cheng X, Mann GE. Effects of 4-hydroxynonenal on vascular endothelial and smooth muscle cell redox signaling and function in health and disease. Redox Biol. 2013; 1:319-331.

17. Tanito M, Agbaga MP, Anderson RE. Upregulation of thioredoxin system via Nrf2-antioxidant responsive element pathway in adaptive-retinal neuroprotection in vivo and in vitro. Free Radic Biol Med. 2007; 42:1838-1850.

18. Singh SP, Niemczyk M, Saini D, Sadovov V, Zimniak L, Zimniak P. Disruption of the mGsta4 gene increases life span of C57BL mice. The journals of gerontology Series A, Biological sciences and medical sciences. 2010; 65:14-23.

19. Dalleau S, Baradat M, Gueraud F, Huc L. Cell death and diseases related to oxidative stress: 4-hydroxynonenal (HNE) in the balance. Cell Death Differ. 2013; 20:1615-1630.

20. Smathers RL, Fritz KS, Galligan JJ, Shearn CT, Reigan P, Marks MJ, Petersen DR. Characterization of 4-HNE modified L-FABP reveals alterations in structural and functional dynamics. PLoS One. 2012; 7:e38459.

21. Siems WG, Zollner $H$, Grune $T$, Esterbauer $H$. Metabolic fate of 4-hydroxynonenal in hepatocytes: 1,4-dihydroxynonene is not the main product. JLipid Res. 1997; 38:612-622.

22. Srivastava S, Liu SQ, Conklin DJ, Zacarias A, Srivastava SK, Bhatnagar A. Involvement of aldose reductase in the metabolism of atherogenic aldehydes. Chem Biol Interact. 2001; 130-132:563-571.

23. Srivastava S, Conklin DJ, Liu SQ, Prakash N, Boor PJ, Srivastava SK, Bhatnagar A. Identification of biochemical pathways for the metabolism of oxidized low-density lipoprotein derived aldehyde-4-hydroxy trans-2-nonenal in vascular smooth muscle cells. Atherosclerosis. 2001; 158:339-350.

24. Hill BG, Haberzettl P, Ahmed Y, Srivastava S, Bhatnagar A. Unsaturated lipid peroxidation-derived aldehydes activate autophagy in vascular smooth-muscle cells. Biochem J. 2008; 410:525-534.

25. Grune T, Davies KJ. The proteasomal system and HNEmodified proteins. MolAspects Med. 2003; 24:195-204.

26. Martinez-Useros J, Garcia-Foncillas J. Obesity and colorectal cancer: molecular features of adipose tissue. Journal of translational medicine. 2016; 14:21.

27. Hu WW, Fengl ZH, Eveleigh J, Iyer G, Pan JS, Amin S, Chung FL, Tang MS. The major lipid peroxidation product, trans-4-hydroxy-2-nonenal, preferentially forms DNA adducts at codon 249 of human p53 gene, a unique mutational hotspot in hepatocellular carcinoma. Carcinogenesis. 2002; 23:1781-1789.

28. Csala M, Kardon T, Legeza B, Lizak B, Mandl J, Margittai E, Puskas F, Szaraz P, Szelenyi P, Banhegyi G. On the role of 4-hydroxynonenal in health and disease. Biochim Biophys Acta. 2015; 1852:826-838.

29. Warburg O. On the origin of cancer cells. Science. 1956; 123:309-314.

30. Juric-Sekhar G, Zarkovic K, Waeg G, Cipak A, Zarkovic N. Distribution of 4-hydroxynonenal-protein conjugates as a marker of lipid peroxidation and parameter of malignancy in astrocytic and ependymal tumors of the brain. Tumori. 2009; 95:762-768.

31. Skrzydlewska E, Stankiewicz A, Sulkowska M, Sulkowski S, Kasacka I. Antioxidant status and lipid peroxidation in colorectal cancer. Journal of toxicology and environmental health Part A. 2001; 64:213-222.

32. Liou GY, Storz P. Reactive oxygen species in cancer. Free Radic Res. 2010; 44:479-496.

33. Murawaki Y, Tsuchiya H, Kanbe T, Harada K, Yashima K, Nozaka K, Tanida O, Kohno M, Mukoyama T, Nishimuki E, Kojo H, Matsura T, Takahashi K, Osaki M, Ito H, Yodoi J, et al. Aberrant expression of selenoproteins in the progression of colorectal cancer. Cancer letters. 2008; 259:218-230.

34. Lushchak VI. Glutathione homeostasis and functions: potential targets for medical interventions. Journal of amino acids. 2012; 2012:736837. 
35. Hensley CT, Wasti AT, DeBerardinis RJ. Glutamine and cancer: cell biology, physiology, and clinical opportunities. J Clin Invest. 2013; 123:3678-3684.

36. Graham NA, Tahmasian M, Kohli B, Komisopoulou E, Zhu M, Vivanco I, Teitell MA, Wu H, Ribas A, Lo RS, Mellinghoff IK, Mischel PS, Graeber TG. Glucose deprivation activates a metabolic and signaling amplification loop leading to cell death. Molecular systems biology. 2012; 8:589.

37. Simons AL, Mattson DM, Dornfeld K, Spitz DR. Glucose deprivation-induced metabolic oxidative stress and cancer therapy. Journal of cancer research and therapeutics. 2009; 5 Suppl 1:S2-6.

38. Dodson M, Liang Q, Johnson MS, Redmann M, Fineberg N, Darley-Usmar VM, Zhang J. Inhibition of glycolysis attenuates 4-hydroxynonenal-dependent autophagy and exacerbates apoptosis in differentiated SH-SY5Y neuroblastoma cells. Autophagy. 2013; 9:1996-2008.

39. Yuneva M, Zamboni N, Oefner P, Sachidanandam R, Lazebnik Y. Deficiency in glutamine but not glucose induces MYC-dependent apoptosis in human cells. The Journal of cell biology. 2007; 178:93-105.

40. Li L, Chen Y, Gibson SB. Starvation-induced autophagy is regulated by mitochondrial reactive oxygen species leading to AMPK activation. Cell Signal. 2013; 25:50-65.

41. Shanware NP, Bray K, Eng CH, Wang F, Follettie M, Myers J, Fantin VR, Abraham RT. Glutamine deprivation stimulates mTOR-JNK-dependent chemokine secretion. Nat Commun. 2014; 5:4900.

42. Bjornsti MA, Houghton PJ. The TOR pathway: a target for cancer therapy. Nature reviews Cancer. 2004; 4:335-348.

43. Abarikwu SO, Pant AB, Farombi EO. 4-Hydroxynonenal induces mitochondrial-mediated apoptosis and oxidative stress in SH-SY5Y human neuronal cells. Basic Clin Pharmacol Toxicol. 2012; 110:441-448.

44. Modica-Napolitano JS, Aprille JR. Delocalized lipophilic cations selectively target the mitochondria of carcinoma cells. Adv Drug Deliv Rev. 2001; 49:63-70.

45. Kim HK, Park WS, Kang SH, Warda M, Kim N, Ko JH, Prince Ael B, Han J. Mitochondrial alterations in human gastric carcinoma cell line. Am J Physiol Cell Physiol. 2007; 293:C761-771.

46. Boland ML, Chourasia AH, Macleod KF. Mitochondrial dysfunction in cancer. Frontiers in oncology. 2013; 3:292.

47. Jose C, Bellance N, Rossignol R. Choosing between glycolysis and oxidative phosphorylation: a tumor's dilemma? Biochim Biophys Acta. 2011; 1807:552-561.

48. Whitaker-Menezes D, Martinez-Outschoorn UE, Flomenberg N, Birbe RC, Witkiewicz AK, Howell A, Pavlides S, Tsirigos A, Ertel A, Pestell RG, Broda P, Minetti C, Lisanti MP, Sotgia F. Hyperactivation of oxidative mitochondrial metabolism in epithelial cancer cells in situ: visualizing the therapeutic effects of metformin in tumor tissue. Cell Cycle. 2011; 10:4047-4064.
49. Picklo MJ, Amarnath V, McIntyre JO, Graham DG, Montine TJ. 4-Hydroxy-2(E)-nonenal inhibits CNS mitochondrial respiration at multiple sites. J Neurochem. 1999; 72:1617-1624.

50. Fan J, Kamphorst JJ, Mathew R, Chung MK, White E, Shlomi T, Rabinowitz JD. Glutamine-driven oxidative phosphorylation is a major ATP source in transformed mammalian cells in both normoxia and hypoxia. Molecular systems biology. 2013; 9:712.

51. Faccenda D, Campanella M. Molecular Regulation of the Mitochondrial F1Fo-ATPsynthase: Physiological and Pathological Significance of the Inhibitory Factor 1 (IF 1). International journal of cell biology. 2012; 2012.

52. Pfeiffer A, Jaeckel M, Lewerenz J, Noack R, Pouya A, Schacht T, Hoffmann C, Winter J, Schweiger S, Schafer MK, Methner A. Mitochondrial function and energy metabolism in neuronal HT22 cells resistant to oxidative stress. Br J Pharmacol. 2014; 171:2147-2158.

53. Minn I, Wang H, Mease RC, Byun Y, Yang X, Wang J, Leach SD, Pomper MG. A red-shifted fluorescent substrate for aldehyde dehydrogenase. Nat Commun. 2014; 5:3662.

54. Rambold AS, Cohen S, Lippincott-Schwartz J. Fatty acid trafficking in starved cells: regulation by lipid droplet lipolysis, autophagy, and mitochondrial fusion dynamics. Dev Cell. 2015; 32:678-692.

55. Isono T, Chano T, Yonese J, Yuasa T. Therapeutic inhibition of mitochondrial function induces cell death in starvationresistant renal cell carcinomas. Sci Rep. 2016; 6:25669.

56. Pike LS, Smift AL, Croteau NJ, Ferrick DA, Wu M. Inhibition of fatty acid oxidation by etomoxir impairs NADPH production and increases reactive oxygen species resulting in ATP depletion and cell death in human glioblastoma cells. Biochim Biophys Acta. 2011; 1807:726-734.

57. Merrill CL, Ni H, Yoon LW, Tirmenstein MA, Narayanan P, Benavides GR, Easton MJ, Creech DR, Hu CX, McFarland DC, Hahn LM, Thomas HC, Morgan KT. Etomoxir-induced oxidative stress in HepG2 cells detected by differential gene expression is confirmed biochemically. Toxicol Sci. 2002; 68:93-101.

58. Bauer G, Zarkovic N. Revealing mechanisms of selective, concentration-dependent potentials of 4-hydroxy-2-nonenal to induce apoptosis in cancer cells through inactivation of membrane-associated catalase. Free Radic Biol Med. 2015; 81:128-144.

59. Schneider L, Giordano S, Zelickson BR, M SJ, G AB, Ouyang X, Fineberg N, Darley-Usmar VM, Zhang J. Differentiation of SH-SY5Y cells to a neuronal phenotype changes cellular bioenergetics and the response to oxidative stress. Free Radic Biol Med. 2011; 51:2007-2017.

60. Soulere L, Queneau Y, Doutheau A. An expeditious synthesis of 4-hydroxy-2(E)-nonenal (4-HNE), its dimethyl 
acetal and of related compounds. Chemistry and Physics of Lipids. 2007; 150:239-243.

61. Doorn JA, Petersen DR. Covalent modification of amino acid nucleophiles by the lipid peroxidation products 4-hydroxy-2-nonenal and 4-oxo-2-nonenal. ChemResToxicol. 2002; 15:1445-1450.
62. Xu GZ, Liu YH, Sayre LM. Independent synthesis, solution behavior, and studies on the mechanism of formation of a primary amine-derived fluorophore representing crosslinking of proteins by (E)-4-hydroxy-2-nonenal. J Org Chem. 1999; 64:5732-5745. 